\title{
Chinese Internet Companies and Their Quest for Globalization
}

\author{
Harlan D. Whatley ${ }^{1}$ \\ ${ }^{1}$ Swiss Management Center, Zurich, Switzerland
}

\begin{abstract}
Chinese internet companies have seen an unprecedented growth over the past decade. However, very few are recognized brands outside of China while some seek to develop their brands in foreign markets. This paper analyzes the marketing strategies of two internet companies: Baidu and Tencent and their quest for globalization.
\end{abstract}

Keywords: Baidu, Tencent, internet, branding, marketing, globalization, China

\section{Introduction}

Innovation efforts by technology companies in China are driven by adding significant value to imported foreign technologies or by developing new products to satisfy specific domestic demands (Li, Chen \& Shapiro, 2010). Firms in the emerging market of China do not possess the $R \& D$ resources that their developed Western counterparts have. However, this is changing as Sino internet enterprises extend their reach globally into foreign markets. Boisot and Meyer (2012) argued that it is easier for Chinese firms to develop their business in foreign markets as opposed to the government controlled domestic market in mainland China. More attention is being directed towards Chinese multinational corporations as they have risen from humble beginnings to becoming recognized as international players in the technology market (Sun, 2009).

This qualitative research paper explores the quest for globalization of two successful Chinese internet companies: Baidu and Tencent Holdings. In this case study, the focus is on the marketing strategies of these expanding multinational enterprises and the challenges they face to become recognized as global brands. All of the firms in this study were founded as private enterprises with no ownership ties to the Chinese government. Furthermore, an analysis of the countries and markets targeted by the firms is included in the study. In addition to a review of the current academic literature, interviews were conducted with marketing and strategy professionals from the perspective firms as well as journalists that closely follow Chinese internet firms and the technology sector. This study on the globalization of Chinese internet firms will contribute to marketing research on this region and sector.

\section{Baidu}

Co-founded in 2000 by Robin Li, who dropped out of a $\mathrm{PhD}$ program at the State University of New York at Buffalo, and Eric $\mathrm{Xu}$, a Silicon Valley venture capitalist, Baidu is China's most popular search engine (Rabkin, 2012). Also, it is the world's leading Chinese language search engine and is ranked as the world's fifth most popular web site (Alexa.com, 2012). The firm is publicly 
traded on the NASDAQ stock exchange and has a market capitalization of $\$ 41.6$ billion (Jiang, 2012). Baidu is ranked 25th on the BrandZ list of the Top 100 Most Valuable Global Brands (MillwardBrown.com, 2012). The name, Baidu, translates from Chinese to English as "hundreds of times" and comes from a Song Dynasty poem (ir.Baidu.com, 2012).

\subsection{Baidu's business model}

Baidu's primary revenue streams come from advertising via Pay per Click (PPC) and search engine optimization via Pay for Placement (P4P). In 2009, Baidu revamped its business model to provide better targeting and a new pricing structure that calculated ad values based on competitors' blind bids (Greenberg, Jie \& Hardy, 2009). In essence, they comingle paid search results with natural ones. Baidu Union, where Baidu's search box field is used on partnering web sites, generates shared revenue with hundreds of thousands of sites. Recently, Baidu planned to generate revenue through online marketing on its popular Baidu Tieba online forum, which will allow clients to market products to the forum's users (Investor's Business Daily, 2012).

\subsection{Marketing strategies}

Baidu's marketing strategy includes effective market segmentation and a focus strategy in order to raise its click rate and increase site traffic (Kotler, Keller \& Lu, 2009). Jiang (2012) stressed that "Baidu benefited tremendously from its early-mover status, a carefully crafted 'China' brand image, and its aggressive (and sometimes questionable) marketing tactics that have involved paid search ranking, site blocking, and paid removal of negative results" (p. 16). According to Kaiser Kuo, Director of International Communications at Baidu, "our international growth strategy is in its very early stages of execution now. We appreciate how dynamic the situation is in all emerging internet markets, and we'll have to be adaptable, responsive, and opportunistic" (personal communication, September 5, 2012).

\subsection{Partnerships}

Frank (2012) emphasized that partnerships are valuable for two reasons: companies will get more market value and gain the trust of its clients and it can provide better services to regular consumers. One of Baidu's strongest partnerships is with the Chinese microblogging site, Sina Weibo, which has over 300 million users and is China's answer to Twitter. The partnership is in response to Baidu's shuttering of their microblogging product, Baidu Talk, and provides cooperation between the two firms in the areas of search, content, platform, technology, and resources (Lau, 2012).

In the fall of 2011, Baidu released Baidu Yi, its mobile operating system built around Android OS. Lee (2012) reported that Baidu partnered with Dell Computer to include Baidu Yi on Dell handsets and tablets. Baidu Yi has been rebranded as Baidu Cloud and was recently launched on a TCL smartphone (Millward, 2012). Other partnerships for Baidu include web-based travel services companies Qunar and Skyscanner. These partnerships are in line with Google's recent acquisition of Frommer's, a U.S. travel services company (Olanoff, 2012).

\subsection{International efforts}

Cooper (2010) observed that "language is an important element in ensuring a consistent brand culture" (p. 13). Baidu announced its intentions to enter the Japanese search market in December 2006 and began server testing in Japan in March 2007 with an official launch in 
January of 2008 with web, image, video and blog search services (Baidu.com, 2012). Like eBay's attempt to crack the Japanese market, this has been a difficult task for Baidu. From 2008 to 2011, Baidu lost 700 million RMB as search engine titans Yahoo! and Google dominate the Japanese market (Hopkins, 2012).

In May of 2012, Baidu launched an office in Australia aimed at helping local firms tap into the potential of China's internet space. Baidu formed a joint venture with a Sydney-based firm, China Search International, and recruited some seasoned talent from Telstra and NineMSN to spearhead the initiative (Apostolou, 2012).

In 2012, Baidu formed BIRC, a joint research lab in Singapore with I2R, to focus on natural language processing technologies, allowing Baidu to research Thai and Vietnamese language capabilities (Wee, 2012). This will give Baidu a better idea of their customer base in these countries, where they already have launched products such as the Hao123 web directory, Baidu Tieba and Tra Da Quan (social networking service) (Russell, 2012). Unfortunately, Hopkins (2012) shared that Baidu has encountered some operating license issues with the Vietnamese government. Wee (2012) noted that Baidu is doing quite well in Indonesia due to the large Chinese ex-pat community there.

\subsection{Competition}

Baidu faces stiff competition from English language search engines Google and Yahoo! but has managed to form an alliance with Microsoft's Bing. With Google's exit from China to Hong Kong in 2010, this created an even better stronghold for Baidu, which now controls $80 \%$ of the Chinese search engine market (Greenberg, Jie \& Hardy, 2009). In China, Baidu is continually being challenged by
Qihoo 360 who touts their browser as being more convenient coupled with superior malware/anti-virus capabilities, despite Baidu's superior content and resources (Zhang, 2012).

\section{Tencent Holdings}

Founded by "Pony" Ma Huateng and four college students in Shenzhen in 1998, Tencent's QQ service offers a chat program, a search engine, an e-commerce marketplace and some of the most popular online games in China (Einhorn \& Stone, 2011). Wu and Frantz (2012) stated that "the mission of the company is to enhance the quality of life through internet value added services" (p. 95). Tencent Holdings is publicly traded on the Hong Kong Stock Exchange and is ranked 37th on the BrandZ list of the Top 100 Most Valuable Global Brands (MillwardBrown.com, 2012). In Chinese, Tencent means, roughly, "galloping message", which is in line with its core instant messaging product known as "QQ" (Tencent.com, 2012).

\subsection{Tencent's business model}

Tencent segments its business into the following groups: Corporate Development Group (CDG), Interactive Entertainment Group (IEG), Mobile Internet Group (MIG), Online Media Group (OMG), Social Network Group (SNG), Technology and Engineering Group (TEG) and Tencent E-Commerce Holding Company (ECC) (Tencent.com, 2012). Recently, Tencent announced that it would adopt an open platform business model, a major strategic shift for the company (Shen, 2012).

Tencent entered into a partnership with Zynga, the US game maker best known for games like FarmVille, which it created for Facebook. China Economic Review (2012) affirmed that the breadth of Tencent's games business includes 
mobile applications, social games, online shooters and massively multiplayer roleplaying games (MMORPGs). In 2011, online games accounted for 5.3 billion RMB or $55 \%$ of Tencent's revenue (Shen, 2012). Tencent faces fierce competition in the online games market in China from Shanda, Netease and ChangYou (Olsen, 2011), although China Economic Review (2012) argued that online games are waning in popularity in China. The open platform approach may in part be a response to heated competition, such as the Twitter-like micro-blogging service, or weibo, introduced by Sina, a Tencent competitor, in 2009. Leveraging its enormous reach, Tencent launched its own weibo in 2010 (Rapoza, 2012).

\subsection{Marketing strategies}

$\mathrm{Wu}$ and Frantz (2012) asserted that Tencent's marketing approach includes forward orientation, independent innovation and national brands creation. Tencent strongly utilizes strategic partnerships with leading domestic and foreign brands. Some of Tencent's partnerships include Vinagame (Vietnam), LevelUp (Singapore), Epic Games (USA), Activation Blizzard (USA) and Zynga (USA). In 2011, Tencent partnered with Sky-mobi Limited, the leading mobile application store in China, to promote Tencent's QQ mobile browser via Skymobi's Maopao application store product (Worldwide Telecom, 2011).

In addition to online games, other forms of media and entertainment are of interest to Tencent. Flannery and Chen (2011) contended that:

Internet and mobile communicationsrelated companies are looking to add new forms of online entertainment content. And with China's government easing rules on the content business and "cultural" industry of late, companies that previously had no major connection to the media or content business are looking to get in.

Tencent set up a 500 million RMB investment fund in April of 2011 focused on online entertainment content that included a $4.4 \%$ stake in Huayi Brothers Media, producer and distributor of some of China's most popular film and television productions (Coonan, 2012).

Gaopeng is a fledgling joint venture between Tencent and Groupon and is the eighth largest daily deal site in China (Ollier, 2011). Another joint venture is with Tencent, Alibaba and Ping An Insurance, which is risky, as the three firms are looking to insure online buyers against internet fraud in China (Young, 2012). In May of 2011, Tencent invested in the Asian travel portal, eLong.com, mimicking the online travel strategies of Baidu and Google (Tencent.com, 2012).

\subsection{International efforts}

As part of their international strategy, Tencent launched an English language version of their website called ImQQ.com. iPhone and Android users can download English versions of QQ to their smartphones at no cost to the end user. The style of QQ's English version is in line with the aesthetic of Westerners and is very user friendly (Wu \& Frantz, 2012).

Outside of China, Tencent has penetrated India, Singapore, Thailand and Vietnam. In India, Tencent signed a licensing and franchise agreement with MIH in 2008 and owns a $20 \%$ stake in the gaming platform, Ibibo (Wu \& Frantz, 2012). Like China, India has a rapidly developing internet culture that is migrating to smartphone applications. Tencent's new mobile social networking application, Weixin (WeChat in English) is available via the iOS, Android, Symbian and Windows operating systems and delivers text, voice and video in nine languages including Arabic, English, Portuguese, Thai and Vietnamese 
(Hopkins, 2012). In 2010, Tencent invested in Sanook, Thailand's most popular web portal (Tencent, 2012). In Indonesia, Tencent released a localized cross-platform chat application called Qute, which has some Facebook-like features and has over 1 million downloads since its June 2012 launch (Hopkins, 2012). S. Millward reported that there are currently some 3 million QQ International users in Indonesia and that Qute is one of the fastest growing technology products since Facebook (personal communication, September 11, 2012).

\subsection{Competition}

The Instant Messenger (IM) market is dominated by Windows Live Messenger with a $64 \%$ share followed by Microsoftowned Skype with an $18.6 \%$ share. Yahoo! Messenger has a $7.2 \%$ share and Tencent's QQ has a $2.9 \%$ share with Google Talk tailing behind with a $1.9 \%$ share (OPSWAT, 2012). For social networking, Facebook is the worldwide player while Tencent's opportunity in America is with online games, where they show no signs of slowing down.

\section{Conclusion}

Vaughn (2012) asserted that "China is actively seeking to export more than just the rest of the world's manufactured goods and to develop strong brands that can hold their own both at home and on the world stage" (p. 3). Shelly Lazarus of Ogilvy \& Mather stated:

Chinese brands are facing the same issues that national brands from other countries must address when they go overseas. Like their international counterparts, Chinese brands have to establish and maintain an 'emotional' bond with local consumers, no matter the market. This is a challenging goal for any company seeking to partake in the global economy. (Yong, 2005).

Li, Chen and Shapiro (2011) observed that "the stronger a firm's marketing efforts, the stronger the positive effect of exporting activities on its product innovation" (p. 13). Friedman (2012) argued that the key to China's global business reach is a new generation of Chinese innovators who are low cost, but high skilled. Global brands must strive for superiority on basics like the brand's price, performance, features and imagery and must learn to manage brands' global characteristics (Holt, Quelch \& Taylor, 2004, p. 73).

The research in this case study shows that Baidu's scale of Chinese language customers has given them the ability to move into other Asian countries, but without English language capabilities, they still have a long way to go in other regions. Tencent, via an aggressive acquisition agenda, has made its presence known in the online games world and, unlike Baidu, offers English language products and services.

Chinese technology firms have built up large cash reserves over the past two decades, allowing them to form joint ventures and acquire firms related to their business in foreign countries, despite cultural, political and regulatory barriers. In the rapidly developing world of technology, Chinese internet firms have leveraged their popularity and scale in China and are positioned to become global market leaders.

\section{References}

[1] Alexa.com (2012). Baidu.

[2] Apostolou, N. (2012). Baidu sets up shop in Australia: China Googleslayer wants your searches. The Register.

[3] Baidu Investor Relations (2012). About Baidu 
[4] Boisot, M. \& Meyer, M.W. (2012). It's easier for small Chinese firms to go international than national. Chinese Management Insights, 1(1), $9-11$

[5] China Economic Review (2012). The legend of Tencent: Diversification wins out in a slow market. China Economic Review, 23(9), 20 - 20.

[6] Coonan, C. (2012). Tencent buys Huayi Bros. stake. Variety.com.

[7] Cooper, L. (2010). Five strategies for a successful global brand. Marketing Week.

[8] Einhorn, B. \& Stone, B. (2011). March of the penguins. Bloomberg Businessweek, 4241, 68 - 73.

[9] EIU (2010). Deal watch. Business China, 7.

[10] Flannery, R. \& Chen, M. (2011). China web giant Tencent buys $4.6 \%$ stake in movie studio. Forbes.com.

[11] Frank, R. (2012). Baidu: Ready to skyrocket on partnerships. Seeking Alpha.

[12] Friedman, T.L. (2012). In China we (don't) trust. The New York Times.

[13] Greenberg, A., Jie, L. \& Hardy, Q. (2009). The guy who's beating Google. Forbes, 184(6), 82 - 87. Retrieved from http://www.ebscohost.com

[14] Holt, D.B., Quelch, J.A. \& Taylor, E.L. (2004). How global brands compete. Harvard Business Review, 82(9), $68-75$.

[15] Hopkins, J. (2012). Baidu and Tencent set sail. TechRice.

[16] Investor's Business Daily (2012). Baidu seeks non-search revenue. Investor's Business Daily.

[17] Jiang, M. (2012). Internet companies in China: Dancing between the party line and the bottom line. Asie.Visions, 47, 1- 50.

[18] Kotler, P., Keller, K.L. \& Lu, T. (2009). Marketing management in China. Singapore: Pearson.
[19] Lau, A. (2012). Baidu partners with Sina to reinforce mobile search in China. Search Engine Watch. Retrieved from http://searchenginewatch.com/

[20] Lee, M. (2012). Dell and Baidu team up for tablets, mobiles. Reuters.com. Retrieved from http://www.reuters.com

[21]Li, J., Chen, D., \& Shapiro, D.M. (2010), Product innovations in emerging economies: The role of foreign knowledge access channels and internal efforts in Chinese firms, Management \& Organization Review, 6(2), 243-66.

[22]MillwardBrown.com (2012a). BrandZ Top 100 Most Valuable Global Brands.

[23]MillwardBrown.com (2012b). BrandZ Top 50 Most Valuable Chinese Brands.

[24] Millward, S. (2012). Baidu still pushing its OS, today launches on third phone. TechinAsia.com.

[25]Olanoff, D.(2012). Baidu has chosen Skyscanner as its international flight search partner. Insider/The Next Web.

[26]Ollier, P. (2011). China business sells counterfeit watches. Managing Intellectual Property, 214, 75 - 75.

[27] Olsen, R. (2011). Tencent jumps after earnings surge $61 \%$. Forbes.com.

[28]OPSWAT (2012). Instant messenger market share report.

[29]Rabkin, A. (2012). The Tao of the sea turtle. FastCompany, 162, 78 99.

[30]Rapoza, K. (2012). China's weibos vs. US Twitter: And the winner is? Forbes.com.

[31]Russell, J. (2012). Baidu continues to eye overseas opportunities as Tieba Vietnam launch is confirmed. The Next Web/Asia. 
[32]Shen, A. (2012). Tencent rejigs to improve reach beyond online games. Forbes.com, 55 - 55.

[33]Sun, S.L. \& Liang, H. (2010). International value creation through private equity: Cases of Chinese outward ventures. LSE Alternative Investment Research Conference (London).

[34]Tencent.com (2012). About.

[35]Vaughn, J. (2012). Remaking 'made in China'. JWT Intelligence.

[36]Worldwide Telecom (2011). SkyMobi/Tencent form strategic partnership. Worldwide Telecom, 23(3), $1-8$.
[37] Wee, W. (2012) Baidu opens lab in Singapore to research Thai, Vietnamese search know-how. TechinAsia.com.

[38] Wu, J.P. \& Frantz, T.L. (2012). Largest IM platform in China Tencent's QQ. Journal of Business Case Studies, 8(1), 95 - 102.

[39] Young, D. (2012). Alibaba, Tencent, Ping An JV: insuring failure. South China Morning Post.

[40] Zhang, J. (2012). Baidu vs. Qihoo: Search superiority outweighs convenience. Seeking Alpha. 